\title{
Protein Profile Changes of Two Chinese Fir Genotypes under Short-term Water Deficit
}

\author{
Guochang Ding ${ }^{1,2 \#}$, Weizhi Guo ${ }^{1 \#}$, Shaoning Ruan ${ }^{1,2}$, Shubin $\mathrm{Li}^{1,2}, \mathrm{Yu}^{\mathrm{C}}$ Chen $^{1,2}$ \\ Sizu $\operatorname{Lin}^{1,2^{*}}$ \\ ${ }^{1}$ Forestry College of Fujian Agriculture and Forestry University, Fuzhou 350002, China \\ ${ }^{2}$ Chinese Fir Engineering Research Center of Fujian, Fuzhou, Fujian 350002, China \\ 1email:fjdgc@fafu.edu.cn \\ * Corresponding author: szlin53@126.com,+8659183789302 \\ \# These authors contributed equally to this work
}

Keywords: Cunninghamia lanceolata,Chinese fir ,water deficit, proteome.

Abstract. Chinese fir (Cunninghamia lanceolata) is an important commercial timber species in China. In the recent years, seasonal droughts occurred frequently in the fir growing areas and made a great impact on its production. In this study, PEG-6000 was used to simulate water deficit, while the drought-resistant FS43 and drought sensitive FS38 fir strains were selected as experimental materials. A two-dimensional electrophoresis technology was used for proteome analysis of leave protein comparisons between the two fir strains under water deficit. A total number of 24 differentially expressed protein spots were detected, of which five were identified by the tandem mass spectrometry and divided into four categories: (a) Functional enzymes involved in photosynthesis: the light-harvesting chlorophyll a/b-binding proteins, ribulose-1, 5-bisphosphate carboxylase/oxygenase; (b) Functional enzymes involved in osmotolerance: myo-inositol 1-phosphate synthase; (c) Functional enzymes involved in carbohydrate metabolism: granule-bound starch synthase I; (d) A conifer specific antioxidant stress-related functional enzyme. Under water deficit, these enzymes with obvious differences in protein expression levels might be involved in the regulation of fir responses to seasonal drought stress.

\section{Introduction}

In recent years, due to the impact of the greenhouse effect and global warming, long-term droughts and other extreme weather conditions occurred in areas with plenty of rain history. Drought has become a world problem, which is seriously affecting the growth and distribution of plants(Egert and Tevini, 2002; Larcher, 1995; Trifilò et al., 2014; Upadhyaya and Panda, 2004). The drought induced biological effects on plants are complicated and when the drought stress is not too severe, the plant metabolisms can develop a series of changes in order to adapt to adverse environmental factors for maintaining normal plant physiological activities, prevent system brake down and also adapt to drought environments(Flexas and Medrano, 2002; Lawlor and Cornic, 2002). However, among all kinds of adversities, drought is the most serious one, which affect plant production as an abiotic stress factor(Chaves et al., 2003; Somerville and Briscoe, 2001). Therefore, investigating important drought-resistant genes to improve plants drought resistance and cultivate the drought tolerance, became an urgent need and important direction for plant breeding. Chinese fir (Cunninghamia lanceolata (Lamb ). Hook) is a coniferous evergreen timber tree of the cypress family [Cupressaceae], which is native to East Asia and an excellent timber species, because of its fast growth, good material, versatile and high yield and therefore the main afforestation tree species in the southern provinces of China. The National fir forest area includes 9.11 million ha and reserves amounted to 350 million $\mathrm{m}^{3}$, while its grow area and nationwide timber volume has accounted at $30.4 \%$ and $28.2 \%$, respectively(Lei, 2005). However, seasonal or extreme drought can result in serious decline of fir growth. In 2003, the annual rain precipitation was only $59.98 \%$ of the average level in the 
Fujian Province, which led to a 54.3\% decrease of 1-year-old Chinese fir average diameter and a 36.4\% decrease of average tree height. The 2-year-old Chinese fir stem diameter and tree height growths in the year 2003 were reduced to $38.8 \%$ and $34.2 \%$, respectively(Lin, 2004). In most of the specific fir growth areas, which produce $70 \%$ of the total Chinese fir, the precipitations are much lower than in the central Chinese area and therefore, to research fir drought resistance might greatly improve the productivity of fir forests. In the past 10 years, researches on plant drought resistance have made significant progress not only from the morphological, physiological and resistance breeding aspects, but also on the cell and molecular levels. Genes associated with drought resistance responses, including scavenging reactive oxygen species, inducing protein folding, degradation and protein synthesis have been identified to improve the draught resistance of plants (Bray, 2004; Hasegawa et al., 2000; Valliyodan and Nguyen, 2006; Yamaguchi-Shinozaki and Shinozaki, 2006) and various studies have shown, that proteomics research is one of the most effective ways to study plant drought related proteins (Hajheidari et al., 2005; Riccardi et al., 1998; Salekdeh et al., 2002; Yoshimura et al., 2008). However there are only few reports on fir drought research, which were mainly involved in physiological responses to fir drought(Liu et al., 1998a,b; Wei et al., 2005) and genotype selection(Liu et al., 1998b), but there was no report about fir drought based on protein screening studies. This study used a PEG-6000 simulated water deficit (Michel and Kaufmann, 1973) response model of drought-tolerant FS43 and draught sensitive FS38 fir strains and we investigated proteome differences of the 2 strains under water deficiency by a two-dimensional electrophoresis.

\section{MATERIAL AND METHODS}

\section{Material}

The one year cutting seedling used drought resistant and sensitive fir strains (No. FS43, FS38) were provided by the Fir Research Center of Fujian.

\section{Experimental Design}

Three FS43 and FS38 fir plants were sampled with 3 repeats. The roots were washed with water, disinfected by a $0.5 \% \mathrm{NaClO}$ solution, rinsed again three times with pure water and then cultured for 5 days in 1L nutrient solution to help the plants adapt to the hydroponic environment and avoid death due to sudden changes in light, temperature and ventilation status. Then the solution was replaced by PEG6000 + Hoagland nutrient solution with 30\% culture stress concentration (Ranjbarfordoei et al., 2001). At 0 , 24th and 48th hour, Fv/Fm was measured with Chlorophyll fluorescence imaging (FluorCam 700MF, P.S. instruments ,Brno, Czech Republic) and at 0 and 48th hour, leaves from the top, middle and bottom part of the FS43 and FS38 plants were clipped and transported to the laboratory in liquid nitrogen for the following protein extractions and two-dimensional electrophoresis.

\section{Two-dimensional electrophoresis}

The two-dimensional gel electrophoresis was done under the same experimental conditions by Yang M (Yang et al., 2007). The gels were scanned and analysed by Image Master 2D Platinum 7.0 software for two-dimensional electrophoresis pattern analysis. The protein spots with significant differences was screened out and MALDI-TOF-TOF tandem mass spectrometry identifications were completed by the Proteome Research Center of the Fudan University. According to the mass peak data, protein database searches were performed using the Mascot search software

\section{RESULTS}

\section{The effects of water deficit on the Photosynthetic physiology}

$\mathrm{Fv} / \mathrm{Fm}$, one of the most commonly used parameters in chlorophyll fluorescence, is called maximal photochemical efficiency of PS II, which reflects the capability of light utility of PS II. Fv/Fm of 2 Chinese fir genotypes gradually decreased with the passage of stress time. After $48 \mathrm{~h}$ under water deficit ,Fv/Fm of F43 is 0.754 , but FS38 is only 0.707 (less than 0.75 , indicating that some damage has occurred.)(Fig.1) 


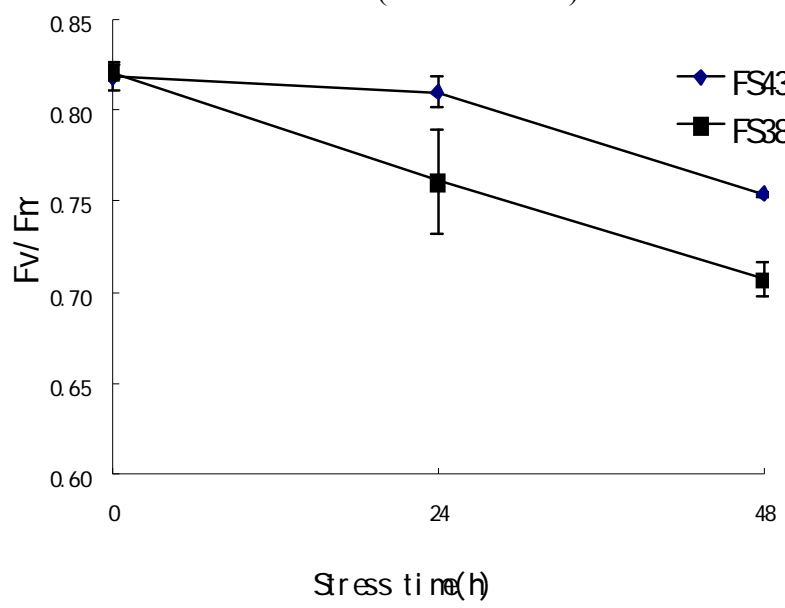

\section{Analysis of leave protein expression profile differences between FS38 and FS43 fir strains under water deficit}

Total proteins were separated by $2 \mathrm{D}$ gel electrophoresis and then analysed by the Image Master 2D Platinum 7.0 software. The results showed that the different fir strains have partly different protein expression characteristics as water deficit response. The sensitive fir FS38 showed 23 different protein spots following the water deficit, in which 18 protein spots were up-regulated and five protein spots were newly generated (Fig. 2 and Tab.1). The drought resistant type FS43 generated 12 different protein spots from which ten showed up-regulated expression and one was newly expressed and one protein disappeared (Fig. 3 and Tab.1).
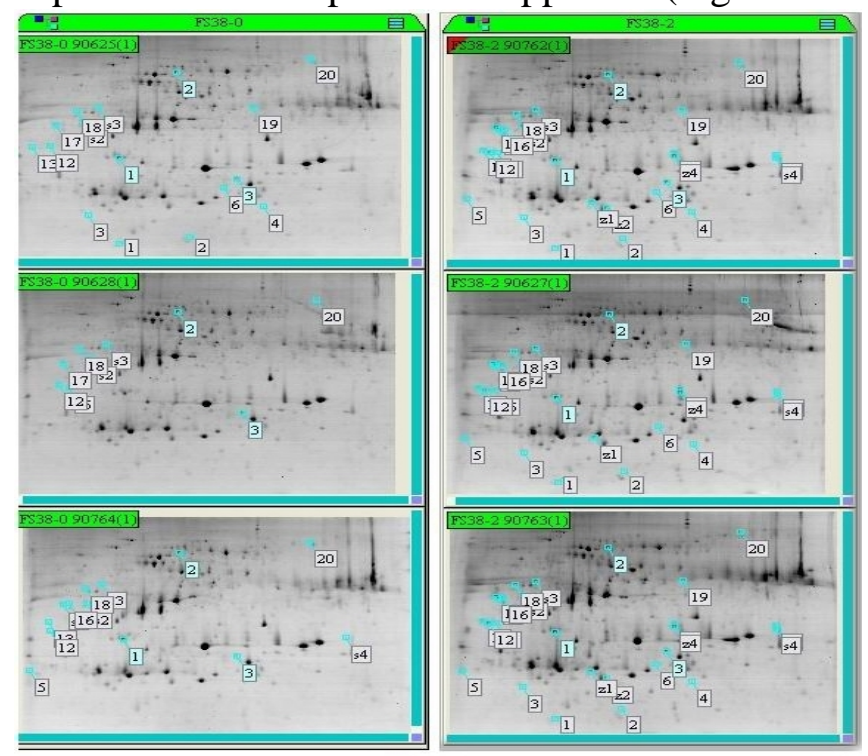

Fig. 2 2-DE maps of differentially expressing proteins in FS38 Chinese fir leaves under water deficit. (Note: The number and letter are indicating the differential expressed proteins)

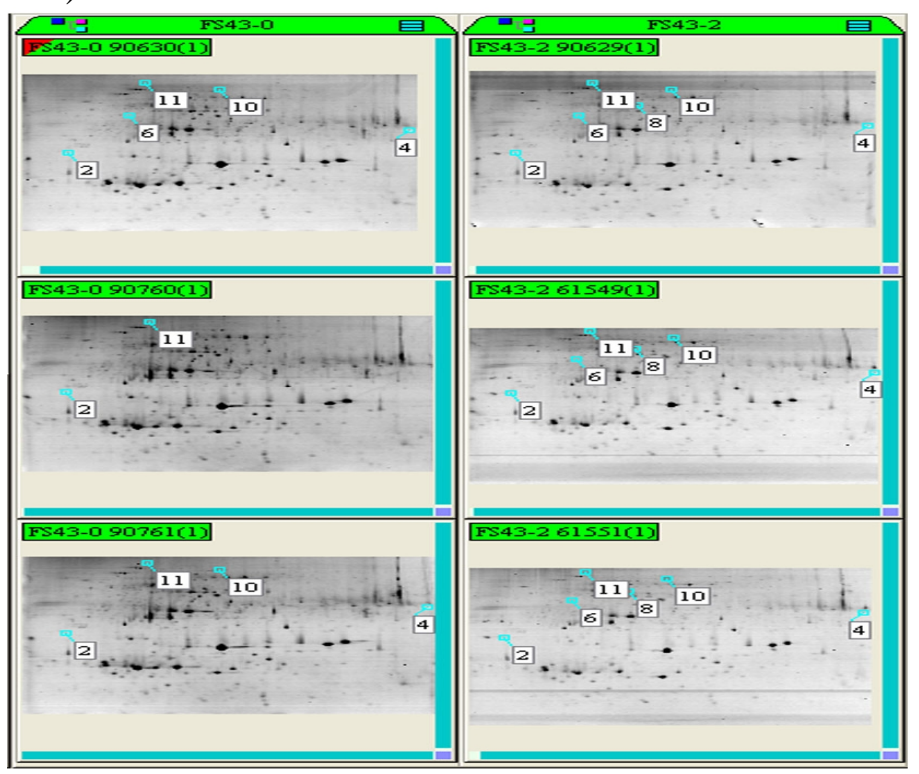

Fig.3 2-DE maps of differentially expressed proteins in the FS43 Chinese fir leaves under water deficit. (Note: The numbers and letters indicating the differential expressed proteins)

The protein expression differences in the single fir strains before and after water deficit can only be explained by molecular water deficit responses in this specific fir genotypes, but does not represent the entire fir population in terms of water deficit responses. Therefore, this study was performed as comprehensive comparison of protein expressions before and after water deficit between the drought-resistant type FS43 and the sensitive type FS38. In total, following water deficit, 11 significant protein spot differences were screened out, including 9 up-regulated proteins, 1 newly synthesised protein and 1 protein disappeared (Fig4. and Tab.1). 


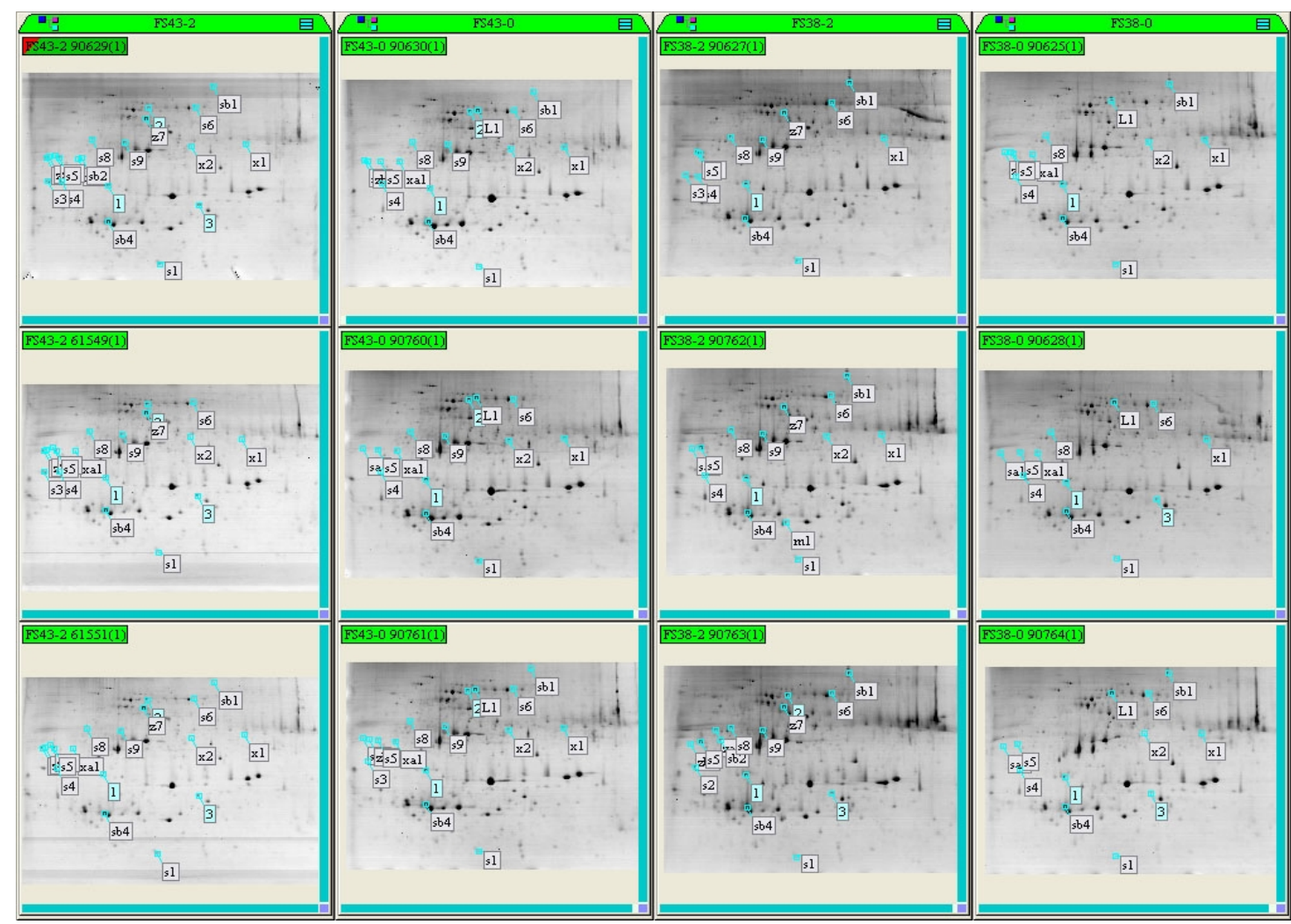

Fig.4 2-DE maps of differentially expressed proteins in both Chinese fir FS43 and FS38 leaves under water deficit. (Note: The numbers and letters indicating the differential expressed proteins)

\section{Mass spectrometry analyses of different protein spots identified from different fir strains under water deficit}

In this study, differences of leave protein expression pattern from fir FS38 and FS43 strains were analysed separately and comprehensively a total number 24 significant protein spot differences (Tab.1) were selected for further MALDI-TOF-TOF tandem mass spectrometry and Mascot protein database blast analyses. Finally five protein spots were identified (Table 2, the identification success rate was $21 \%)$.

\section{DISCUSSION}

The plant physiological responses to water deficit is complicated and heterogeneous, including declined stomatal conductance and photosynthetic activity, imbalance of water metabolism, increased oxidative damage and biomass allocation changes (Flexas and Medrano, 2002; Lawlor and Cornic, 2002). These physiological effects can further induce corresponding various types of functional proteins. Our results showed that water deficit significantly affected the protein expression in fir, which might be related to the drought-resistance mechanisms.

In our studies, the differential protein spot 3 was chlorophyll a/b-binding protein, which is part of the light harvesting complex (LHC). The leave LHC proteins in the drought-resistant strain FS43 and the drought sensitive strain FS38 were both up-regulated under water deficit (Tab.1). LHC is encoded by the chlorophyll a/b binding protein $(\mathrm{Cab})$ multi-gene family and plays an important role in maintaining the structure of the thylakoid membrane, regulating the distribution of excited energy between photosystem I (PSI ) and photosystem II (PS II ), light protection and adaption processes to various environments. As a light receptor, LHC can capture or release the excited energy during photosynthesis, and due to its light trapping ability it increases the photosynthetic efficiency (Green et al., 1991). Under drought stress, LHC proteins are linked with other stress-related proteins(Loukehaich et al., 2012; Ricachenevsky et al., 2010; Wang, 2011) and its elevation can 
compensate the plants' otherwise declined photosynthetic rate. The differential protein spot 16 was ribulose-1 , 5-bisphosphate carboxylase/oxygenase large subunit [Camellia oleifera] (RuBisCO), which is the most abundant protein in the leaves, accounting for $30 \%-50 \%$ of the total soluble leave proteins (Feller et al., 2008; Makino et al., 1984). In photosynthesis, RuBisCO catalyzes the ribulose-1 , 5 - bisphosphate carboxylation reaction with $\mathrm{CO}_{2}$ or oxidation reaction with $\mathrm{O}_{2}$. The major product depends on the intracellular $\mathrm{CO}_{2} / \mathrm{O}_{2}$ ratio and with high oxygen levels increased amounts of $\mathrm{RuBP}$ become wasted by photo respiration. Various environmental and plant physiological factors as well as various inhibitors affect the RubisCO activity (DaMatta and Hemantaranjan, 2003; Jensen and Bahr, 1977). However, in this study, interestingly the RuBisCO levels in leaves of drought-resistant strain FS43 and sensitive strain FS38 were both up-regulated following the water deprivation (Tab.1). This result is in contrast with other publications, which reported decreased levels (Vu and Gesch, 1999) or even abolition of RuBisCO, following drought stress(Reddy et al., 2004), but in agreement with contrary reports from Rizhsky (2002) and Xu (2009). Therefore, the role of RuBisCO in water deficit response needs further investigations.

Functional enzymes of anti-permeation play an important role in the fir drought stress response

In plants, osmoregulation is an important physiological mechanism to adapt to adversities and an effective way to tolerate water deficiency. The osmotic adjustment of plant cells depends on inorganic ions, the accumulation of small organic molecules (including small protein molecules), as well as their spatial transfer (Spickett et al., 1992). The differential protein spot 8 was identified as the myo-inositol-1-phosphate synthase [Gossypium hirsutum] (MIPS), which is a hydrophilic protein, commonly located in the cytoplasm of prokaryotes and eukaryotes and an important osmoprotectant. It is not only involved in the phosphorus storage of plant cells, but also plays an important role in the protection of plants against externe stress damage, formation of the plant cell wall, hormone storage and signal transduction transportations. MIPS converts 6-phosphate glucose into myo-inositol 3-phosphate and an inositol biosynthesis rate-limiting enzyme (Abreu and Aragão, 2007). In this study, in leaves of drought-resistant strain FS43 and sensitive strain FS38, MIPS were up-regulated following water deficit (Tab.1). This result is in concordance with a previous study, which indicated that MIPS plays an important role in drought-resistance (Wei, W. et al., 2010).

\section{The Drought Stress affects the metabolism of carbohydrates}

Environmental factors are important for plants' starch synthesis. With sunshine, starch produced by the plant photosynthesis initially is stored in the chloroplasts. During the night, when photosynthesis is inactive, the starch is broken down into glucose and maltose and transferred out of the chloroplast for the synthesis of sucrose as well as maintenance of the plant metabolism, leaf respiration, growth and development (Zeeman et al., 2007). The differential protein spot 11 was granule bound starch synthase I [Ipomoea cordatotriloba] (GBSS). GBSS I is a key enzyme for starch synthesis and present in the cereal starches known as the waxy protein. GBSS I binds to starch granules and synthesizes amylose, which remains in an un-branched starch conformation state in the absence of a branching enzyme. GBSS I regulates the synthesis and content of amylose in plant cells and therefore its expression change affects the starch's retrogradation and pasting properties. In our study, GBSS I was expressed in leaves before the water deficit $(0 \mathrm{~h})$, but disappeared during the stress response in both the drought-resistant FS43 and sensitive strain FS38. The GBSS I level is known to be easily affected by the environment, while subjected to abiotic stress, the plants switch to starch synthesis reduction (Fábián et al., 2011; NICOLAS et al., 1985). Also in our experiment, the inhibition of GBSS I following water deficit has been one of the drought-resistant mechanisms of fir leaves to improve their drought responses.

\section{Drought stress induces other conifer specific oxidative stress related enzymes}

Following external environmental stimulations, plants produce a series of adaptive responses including protective enzymes against oxidative stress damages, like peroxidase (POD), superoxide dismutase and catalase (CAT) (Reddy, et al., 2004). The differential protein spot 9 was most similar to an unknown protein in the radiata pine with the NCBI's match score of 179(Puzio et al., 2009) and a match score with POD of up to 119 (Table 2). PODs have a dual nature of function. On one hand, POD 
is expressed during adversities in the early stage of aging in order to quench $\mathrm{H}_{2} \mathrm{O}_{2}$, thus during the early stress its activity is generally increased. On the other hand, POD can also be expressed during adversities or during certain stages of plant late aging and participate then in the generation of reactive oxygen species, the degradation of chlorophyll and induction of membrane lipid peroxidation, being used as an aging indicator. In general, its primary role is considered as being the latter one(Zhang and Kirkham, 1994). Therefore, the questions whether the newly formed protein spot 9 only exists in conifers, its similar structure with POD, as well as its role as a particularly drought mechanisms related new protein still needs further investigations.

In conclusion, plant proteome is influenced by environmental stresses, in particular, this study showed that water stress greatly affected the expression of proteins in Chinese Fir. Identified proteins are involved in several physiological mechanisms, and could be implicated in drought response, which play a key role in photosynthesis, osmotic adjustment and decrease in energy consumption to employ a series of strategies to survive the water stress(Fig.5).

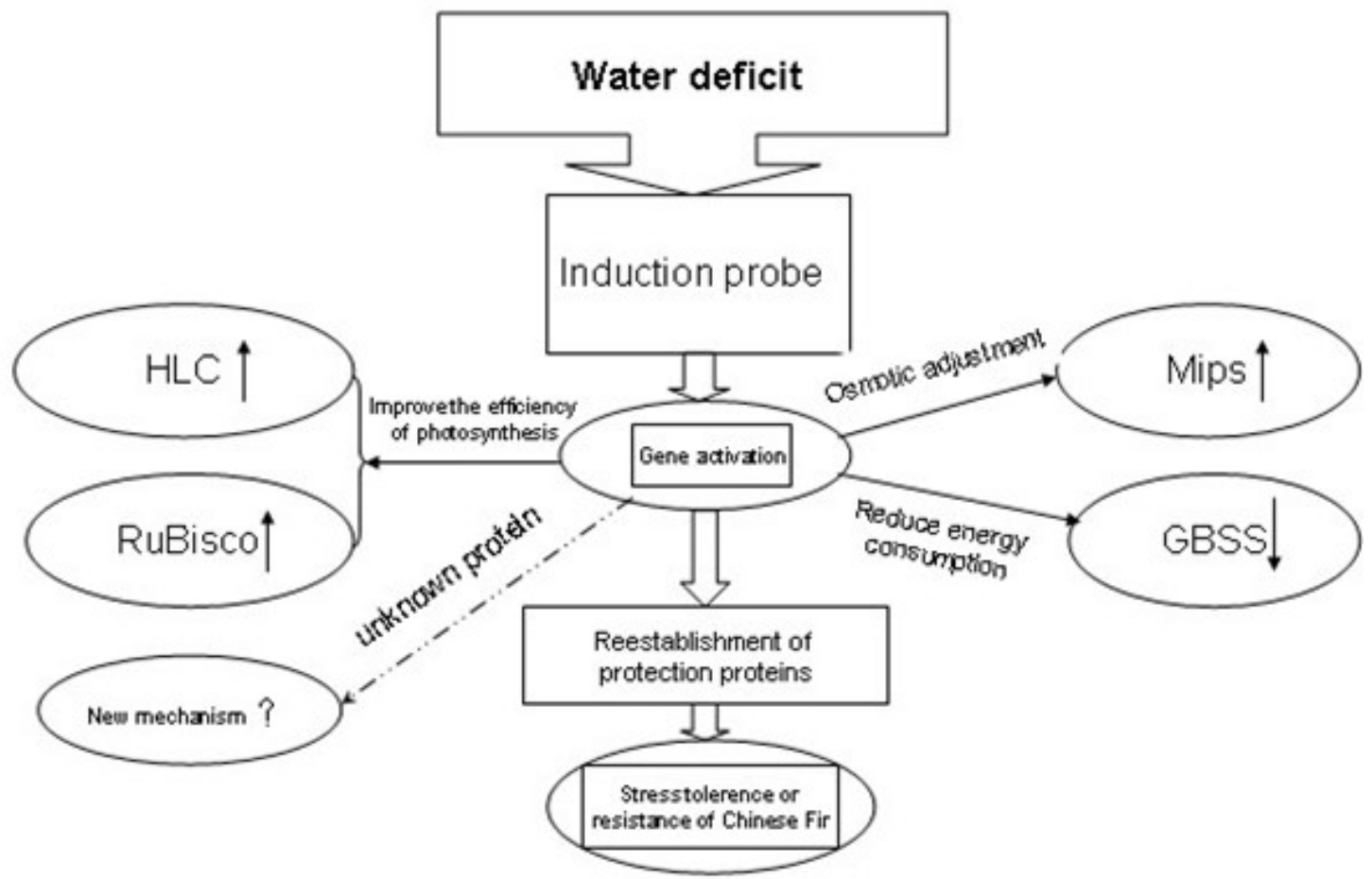

Fig.5 The Chinese Fir response to osmotic stress and the stress signals trigger the downstream signaling process which activate stress-responsive mechanisms to re-establish protection proteins.

The knowledge of Chinese fir water stress-related proteins and strategies of surviving the water stress could help to understand the molecular basis of drought response, and could provide the key of marker genes selection in order to develop Chinese fir varieties exhibiting an increased water-stress tolerance. So these proteins could be chosen as putative biomarkers to understand physiological effects at molecular levels, and to improve drought resistant lines of Chinese fir.

However in our studies, limited proteins are identified. To develop Chinese fir proteomics to its full potential, more efforts should be concentrated on the revelation and identification of more proteins in future studies. For example, the use of a more sensitive staining protocol and very narrow gradients will enable many more proteins to be visualized and resolved. And protocols also should be optimized for the extraction and solubilization of proteins.

\section{ACKNOWLEDGMENTS}

Research was founded by National Basic Research Program of China (No. 2013CB127402), major 
special projects of industry-university-research cooperation of Fujian province, China (No.2012N0010) and National Natural Science Foundation of China (No. 31272229).

\section{REFERENCES}

Abreu, E. F., \& Aragão, F. J. 2007. Isolation and characterization of a myo-inositol-1-phosphate synthase gene from yellow passion fruit (Passiflora edulis f. flavicarpa) expressed during seed development and environmental stress. Annals of botany. 99(2): 285-292.

Bray, E. A. 2004. Genes commonly regulated by water-deficit stress in Arabidopsis thaliana. Journal of Experimental Botany. 55(407): 2331-2341.

Chaves, M. M., Maroco, J. P., \& Pereira, J. S. 2003. Understanding plant responses to drought-from genes to the whole plant. Functional Plant Biology. 30(3): 239-264.

DaMatta, F., \& Hemantaranjan, A. 2003. Drought as a multidimensional stress affecting photosynthesis in tropical tree crops. Advances in plant physiology. 5: 227-265.

Egert, M., \& Tevini, M. 2002. Influence of drought on some physiological parameters symptomatic for oxidative stress in leaves of chives (Allium schoenoprasum). Environmental and Experimental Botany. 48(1): 43-49.

Fábián, A., Jäger, K., Rakszegi, M., \& Barnabás, B. 2011. Embryo and endosperm development in wheat (Triticum aestivum L.) kernels subjected to drought stress. Plant cell reports. 30(4): 551-563. Feller, U., Anders, I., \& Mae, T. 2008. Rubiscolytics: fate of Rubisco after its enzymatic function in a cell is terminated. Journal of Experimental Botany. 59(7): 1615-1624.

Flexas, J., \& Medrano, H. 2002. Energy dissipation in $\mathrm{C}_{3}$ plants under drought. Functional Plant Biology. 29(10): 1209-1215.

Green, B. R., Pichersky, E., \& Kloppstech, K. 1991. Chlorophyll a/b-binding proteins: an extended family. Trends in biochemical sciences. 16: 181-186.

Hajheidari, M., Abdollahian $\square$ Noghabi, M., Askari, H., Heidari, M., Sadeghian, S. Y., Ober, E. S., \& Hosseini Salekdeh, G. 2005. Proteome analysis of sugar beet leaves under drought stress. Proteomics. 5(4): 950-960.

Hasegawa, P. M., Bressan, R. A., Zhu, J.-K., \& Bohnert, H. J. 2000. Plant cellular and molecular responses to high salinity. Annual review of plant biology. 51(1): 463-499.

Jensen, R. G., \& Bahr, J. T. 1977. Ribulose 1, 5-bisphosphate carboxylase-oxygenase. Annual Review of Plant Physiology. 28(1): 379-400.

Larcher, W. 1995. Plants under stress. Springer, Berlin: 321-448.

Lawlor, D., \& Cornic, G. 2002. Photosynthetic carbon assimilation and associated metabolism in relation to water deficits in higher plants. Plant, Cell \& Environment. 25(2): 275-294.

Lei, J. 2005. Forest resources of China. Chinese Forestry, Beijing: 172-173(in Chinese).

Lin , Youle. 2004. Effects of the 2003 drought on the growth of 1-to 3-year- old Chinese fir (

Cunninghamia lanceolata) Plantation. Jour of Fujian Forestry Sci and Tech. 31 (3) : 31-34+49(in Chinese).

Liu, A., \& Feng, L. 1998. Effects of water stress on photosynthetic characters of Chinese fir clones. Journal of Fujian College of Forestry. 18(3): 238-241(in Chinese).

Liu, A., Ma, X., \& Feng, L. 1998. A study on physiological responses of different Chinese fir clones under water stress. Journal of Fujian College of Forestry. 18(1): 28-31(in Chinese).

Loukehaich, R., Wang, T., Ouyang, B., Ziaf, K., Li, H., Zhang, J., Lu, Y., \& Ye, Z. 2012. SpUSP, an annexin-interacting universal stress protein, enhances drought tolerance in tomato. Journal of Experimental Botany. 63(15): 5593-5606.

Makino, A., Mae, T., \& Ohira, K. 1984. Relation between nitrogen and ribulose-1, 5-bisphosphate carboxylase in rice leaves from emergence through senescence. Plant and Cell Physiology. 25(3): 429-437. 
Michel, B. E., \& Kaufmann, M. R. 1973. The osmotic potential of polyethylene glycol 6000. Plant physiology. 51(5): 914-916.

Puzio, P., Blau, A., Walk, T. B., Gipsmans, M., Haake, V., Weig, A., Plesch, G., \& Ebneth, M. 2009. Process for the production of a fine chemical: EP Patent 2,090,662.

Ranjbarfordoei, A., Samson, R., Van Damme, P., \& Lemeur, R. 2001. Effects of drought stress induced by polyethylene glycol on pigment content and photosynthetic gas exchange of Pistacia khinjuk and P. mutica. Photosynthetica. 38(3): 443-447.

Reddy, A. R., Chaitanya, K. V., \& Vivekanandan, M. 2004. Drought-induced responses of photosynthesis and antioxidant metabolism in higher plants. Journal of plant physiology. 161(11): 1189-1202.

Ricachenevsky, F. K., Sperotto, R. A., Menguer, P. K., \& Fett, J. P. 2010. Identification of Fe-excess-induced genes in rice shoots reveals a WRKY transcription factor responsive to Fe, drought and senescence. Molecular biology reports. 37(8): 3735-3745.

Riccardi, F., Gazeau, P., De Vienne, D., \& Zivy, M. 1998. Protein changes in response to progressive water deficit in maize quantitative variation and polypeptide identification. Plant Physiology. 117(4): 1253-1263.

Rizhsky, L., Liang, H., \& Mittler, R. 2002. The combined effect of drought stress and heat shock on gene expression in tobacco. Plant Physiology. 130(3): 1143-1151.

Salekdeh, G. H., Siopongco, J., Wade, L. J., Ghareyazie, B., \& Bennett, J. 2002. Proteomic analysis of rice leaves during drought stress and recovery. Proteomics. 2(9): 1131-1145.

Somerville, C., \& Briscoe, J. 2001. Genetic engineering and water. Science (New York, NY). 292(5525): 2217.

Spickett, C. M., Smirnoff, N., \& Ratcliffe, R. G. 1992. Metabolic Response of Maize Roots to Hyperosmotic Shock An in Vivo 31P Nuclear Magnetic Resonance Study. Plant physiology. 99(3): 856-863.

Trifilò, P., Barbera, P. M., Raimondo, F., Nardini, A., \& Gullo, M. A. L. 2014. Coping with drought-induced xylem cavitation: coordination of embolism repair and ionic effects in three Mediterranean evergreens. Tree Physiology: tpt119.

Upadhyaya, H., \& Panda, S. 2004. Responses of Camellia sinensis to drought and rehydration.

Biologia plantarum. 48(4): 597-600.

Valliyodan, B., \& Nguyen, H. T. 2006. Understanding regulatory networks and engineering for enhanced drought tolerance in plants. Current opinion in plant biology. 9(2): 189.

Vu, J. C., \& Gesch, R. W. 1999. $\mathrm{CO}_{2}$ enrichment eelays a rapid, rrought-Induced recrease in rubisco small subunit transcript abundance. Journal of plant physiology. 155(1): 139-142.

Wei, L., Zhang, X., Hou, Z., Xu, D., \& Yu, X. 2005. Effects of water stress on photosynthesis and carbon allocation in Cunninghamia lanceolata seedlings. Acta Phytoecol. Sin. 29(3): 394r402.

Wei, W., Dai, X., Wang, Y., Chuan, Y., Gou, C.-B., \& Chen, F. 2010. Cloning and Expression Analysis of 1 L-myo-Inositol-1-phosphate Synthase Gene from Ricinus communis L. Z Naturforsch .65(7-8): 501-507.

Xu, G., Li, C., \& Yao, Y. 2009. Proteomics Analysis of Drought Stress-Responsive Proteins in Hippophae rhamnoides L. Plant Molecular Biology Reporter. 27(2): 153-161.

Yamaguchi-Shinozaki, K., \& Shinozaki, K. 2006. Transcriptional regulatory networks in cellular responses and tolerance to dehydration and cold stresses. Annu. Rev. Plant Biol. 57: 781-803.

Yang, M., Chen, W., \& Lin, S. 2007. Optimization of two-dimensional polyaneylamide gel electrophoresis for proteome of Chinese Fir leaves. Journal of Tropical and Subtropical Botany. 15: 438- 442(in Chinese).

Yoshimura, K., Masuda, A., Kuwano, M., Yokota, A., \& Akashi, K. 2008. Programmed proteome response for drought avoidance/tolerance in the root of a $\mathrm{C} 3$ xerophyte (wild watermelon) under water deficits. Plant and cell physiology. 49(2): 226-241.

Zeeman, S., Smith, S., \& Smith, A. 2007. The diurnal metabolism of leaf starch. Biochem. J. 401: 13-28. 
Zhang, J., \& Kirkham, M. 1994. Drought-stress-induced changes in activities of superoxide dismutase, catalase, and peroxidase in wheat species. Plant and cell physiology. 35(5): 785-791.

Tab. 1 The Match Information of Differentially Expressed Protein Spots in Chinese Fir FS43 and FS38 Leaves under Drought Stress

\begin{tabular}{|c|c|c|c|c|c|}
\hline No & $\begin{array}{l}\text { Differential } \\
\text { protein spot }\end{array}$ & Spot source & Ratio & Anova & $\begin{array}{l}\text { Expression } \\
\text { pattern }\end{array}$ \\
\hline spot1 & s9 & both & infinite & 0.10444 & up-regulation \\
\hline spot2 & sb4 & both & 2.432137 & 0.000002 & up-regulation \\
\hline spot3 & s1 & both & 2.103363 & 0.01546 & up-regulation \\
\hline spot4 & sal & both & 9.025532 & 0.00147 & up-regulation \\
\hline spot5 & s3 & both & infinity & 0.33356 & up-regulation \\
\hline spot6 & s4 & both & 18.44363 & 0.00011 & up-regulation \\
\hline spot7 & s5 & both & 2.66129 & 0.01029 & up-regulation \\
\hline spot8 & s6 & both & 3.022759 & 0.000963 & up-regulation \\
\hline spot9 & $\mathrm{z} 7$ & both & infinite & 0.0007 & newly increased \\
\hline spot10 & s8 & both & 2.740887 & 0.100308 & up-regulation \\
\hline spot11 & L1 & both & infinite & 0.00014 & disappear \\
\hline spot12 & 4 & FS43 & 6.061589 & 0.013519 & up-regulation \\
\hline spot13 & 16 & FS38 & 7.871034 & 0.009722 & up-regulation \\
\hline spot14 & $\mathrm{z} 1$ & FS38 & infinite & 0.000458 & newly increased \\
\hline spot15 & $\mathrm{z} 5$ & FS38 & infinite & 0.004522 & newly increased \\
\hline spot16 & $\mathrm{z} 4$ & FS38 & infinite & 0.018836 & newly increased \\
\hline spot17 & 12 & FS38 & 2.741263 & 0.000768 & up-regulation \\
\hline spot18 & 18 & FS38 & 4.518965 & 0.033878 & up-regulation \\
\hline spot19 & 17 & FS38 & 6.949473 & 0.019489 & up-regulation \\
\hline spot20 & 20 & FS38 & 2.560355 & $6.26 \mathrm{E}-05$ & up-regulation \\
\hline spot21 & 19 & FS38 & 5.983174 & 0.010708 & up-regulation \\
\hline spot22 & s2 & FS38 & 2.328587 & 0.055795 & up-regulation \\
\hline spot23 & s1 & FS38 & 3.98845 & 0.046704 & up-regulation \\
\hline spot24 & s4 & FS38 & 3.033373 & 0.122672 & up-regulation \\
\hline
\end{tabular}


Tab. 2 The MALDI-TOF-TOF Identification Results of Differentially Expressed Proteins

\begin{tabular}{|c|c|c|c|c|c|}
\hline No & $\begin{array}{l}\text { Accession No. } \\
\text { (in NCBI) }\end{array}$ & Protein deseription & $\begin{array}{l}\text { Theoretica } \\
\text { l pI/Mw }\end{array}$ & $\begin{array}{l}\text { Protein } \\
\text { Score }\end{array}$ & $\begin{array}{l}\text { Sequence } \\
\text { Coverage } \\
(\%)\end{array}$ \\
\hline spot3 & gi|125620170 & $\begin{array}{l}\text { Chlorophylla/b-binding protein } \\
\text { [Nelumbo nucifera] }\end{array}$ & $\begin{array}{l}5.45 / \\
29047.19\end{array}$ & 110 & 23.42 \\
\hline spot 8 & gi|211906442 & $\begin{array}{l}\text { Myo-inositol-1-phosphate } \\
\text { synthase[Gossypium hirsutum] }\end{array}$ & $\begin{array}{l}5.46 / \\
56403.50\end{array}$ & 168 & 25.29 \\
\hline spot 9 & gi|283799257 & $\begin{array}{l}\text { Sequence } 342 \text { from patent US } \\
7799906 \text { ( Pinus radiata ) }\end{array}$ & $\begin{array}{l}4.43 / \\
1746.81\end{array}$ & 179 & 50.00 \\
\hline spot 11 & gi|158938777 & $\begin{array}{l}\text { Granule bound starch synthase I } \\
\text { [Ipomoea cordatotriloba] }\end{array}$ & $\begin{array}{l}6.37 / \\
46267.65\end{array}$ & 161 & 39.86 \\
\hline spot 16 & gi|290586302 & $\begin{array}{l}\text { Ribulose-1,5-bisphosphate } \\
\text { carboxylase/oxygenase large } \\
\text { subunit [Camellia oleifera] }\end{array}$ & $\begin{array}{l}7.01 / \\
26135.62\end{array}$ & 133 & 73.93 \\
\hline
\end{tabular}

